\title{
Antibiotic-Resistant Vibrios in Farmed Shrimp
}

\section{Renata Albuquerque Costa, ${ }^{1,2}$ Rayza Lima Araújo, ${ }^{1,2}$ Oscarina Viana Souza, ${ }^{1,2}$ and Regine Helena Silva dos Fernandes Vieira ${ }^{1,2}$}

\footnotetext{
${ }^{1}$ Sea Science Institute, Federal University of Ceará, Avenida Abolição 3207, 60165-081 Fortaleza, CE, Brazil

${ }^{2}$ Fisheries Engineering Department, Federal University of Ceará, 60440-900 Fortaleza, CE, Brazil
}

Correspondence should be addressed to Renata Albuquerque Costa; renata.albuq@gmail.com

Received 22 August 2014; Revised 13 October 2014; Accepted 13 October 2014

Academic Editor: David Rodríguez-Lázaro

Copyright (C) 2015 Renata Albuquerque Costa et al. This is an open access article distributed under the Creative Commons Attribution License, which permits unrestricted use, distribution, and reproduction in any medium, provided the original work is properly cited.

\begin{abstract}
Antimicrobial susceptibility pattern was determined in 100 strains of Vibrio isolated from the Litopenaeus vannamei shrimp and identified phenotypically. A high antibiotic-resistance index (75\%) was observed, with the following phenotypic profiles: monoresistance $(n=42)$, cross-resistance to $\beta$-lactams $(n=20)$ and multiple resistance $(n=13)$. Plasmid resistance was characterized for penicillin $(n=11)$, penicillin + ampicillin $(n=1)$, penicillin + aztreonam $(n=1)$, and ampicillin $(n=1)$. Resistance to antimicrobial drugs by the other strains $(n=86)$ was possibly mediated by chromosomal genes. The findings of this study support the conclusion that the cultured shrimps can be vehicles of vibrios resistant to $\beta$-lactam and tetracycline.
\end{abstract}

\section{Introduction}

Bacteria of the Vibrio genus occur naturally in marine, estuarine, and freshwater environments [1] and are notably described as shrimp pathogens [2]. Studies indicate that the antibiotic resistance of vibrios isolated from penaeid culture environment is not unusual [3-5], a fact that apparently constitutes a problem to this type of aquaculture activity [6]. In addition, there is the risk of environmental impact, since the use of antibacterial agents as prophylactic measure in aquaculture favors the selection of resistant bacteria, increasing the probability of transferring resistant genes to human pathogens and land animals [7].

Considering the importance of researching the occurrence of antibiotic-resistant bacteria in marine invertebrates intended for human consumption, this study aimed to determine the susceptibility pattern to antibacterial drugs of vibrios isolated from the hemolymph of Litopenaeus vannamei shrimp.

\section{Materials and Methods}

A total of 100 Vibrio strains from the bacterial collection of the Microbiology Laboratory at the Environmental and
Fish-Sea Sciences Institute (LABOMAR-UFC) were used in this experiment. Only strains previously identified by phenotyping were used [8]. The 100 strains, isolated from the hemolymph of Litopenaeus vannamei, were subjected to identification by a set of biochemical keys [9], using the following tests: arginine dihydrolase, lysine decarboxylase and ornithine decarboxylase, oxidase, indole, ortho-nitrophenyl$\beta$-galactoside (ONPG), Voges-Proskauer, D-glucosamine cs, growth at $0 \%, 3 \%, 8 \%$, and $10 \% \mathrm{NaCl}$, growth at $40^{\circ}$ and $4^{\circ} \mathrm{C}$, citrate, gelatinase, urease, resistance to $\mathrm{O} / 129$, and acid from glucose, sucrose, arabinose, mannitol, and melibiose. The strains had consonant phenotypic profiles with the species $V$. navarrensis $(n=53), V$. brasiliensis $(n=15), V$. parahaemolyticus $(n=10), V$.xuii $(n=8), V$. coralliilyticus $(n=5), V$. cholerae $(n=4), V$. neptunius $(n=2), V$. alginolyticus $(n=1)$, $V$. diazotrophicus $(n=1)$, and $V$. vulnificus B3 $(n=1)$.

All isolates $(n=100)$ were submitted to antibiotic susceptibility pattern tests by disk diffusion method [9]. For the present study, antibiotics used in shrimp industry [4] and human clinical [10] were selected. The following antimicrobials (Laborclin) were tested: nalidixic acid (Nal $30 \mu \mathrm{g})$, ampicillin (Amp $10 \mu \mathrm{g}$ ), aztreonam (Atm $30 \mu \mathrm{g}$ ), cephalothin $(\mathrm{Cpl} 30 \mu \mathrm{g})$, ceftriaxone (Cro $30 \mu \mathrm{g}$ ), ciprofloxacin (Cip $5 \mu \mathrm{g}$ ), chloramphenicol (Clo $30 \mu \mathrm{g})$, streptomycin (Est $10 \mu \mathrm{g}$ ), 
TABLE 1: Antimicrobial resistance in vibrios isolated from the hemolymph of Litopenaeus vannamei shrimp.

\begin{tabular}{lcccccccc}
\hline \multirow{2}{*}{ Species } & $n$ & \multirow{2}{*}{$n \mathrm{R}(\%)$} & \multicolumn{6}{c}{ Resistance } \\
& & & Pen & Tcy & Cpl & Amp & Atm & Cro \\
\hline V. navarrensis & 53 & $38(71,7)$ & 32 & - & 3 & 2 & 7 & 1 \\
V. brasiliensis & 15 & $9(60)$ & 9 & - & 4 & 1 & - & - \\
V. parahaemolyticus & 10 & $10(100)$ & 10 & 9 & 1 & 3 & - & - \\
V. xuii & 8 & $8(100)$ & 8 & - & 4 & 2 & - & - \\
V. coralliilyticus & 5 & $3(60)$ & 3 & - & - & - & - & - \\
V. cholerae & 4 & $4(100)$ & 4 & 3 & - & 2 & 1 & - \\
V. neptunius & 2 & $0(0)$ & - & - & - & - & - & - \\
V. alginolyticus & 1 & $1(100)$ & 1 & - & - & - & - & - \\
V. diazotrophicus & 1 & $1(100)$ & - & - & - & - & 1 & - \\
V. vulnificus $\mathrm{B} 3$ & 1 & $1(100)$ & 1 & 1 & - & - & - & \\
Total & $\mathbf{1 0 0}$ & $\mathbf{7 5}$ & $\mathbf{6 8}$ & $\mathbf{1 2}$ & $\mathbf{1 2}$ & $\mathbf{1 0}$ & $\mathbf{9}$ & $\mathbf{1}$ \\
\hline
\end{tabular}

${ }^{*} n$ : number of isolates. $n$ R: number of resistant isolates. Pen: penicillin G; Tcy: tetracycline; Amp: ampicillin; Cpl: cephalothin; Atm: aztreonam; Cro: ceftriaxone.

gentamicin (Gen $10 \mu \mathrm{g}$ ), imipenem (Ipm $10 \mu \mathrm{g}$ ), nitrofurantoin (Nit $300 \mu \mathrm{g}$ ), penicillin (Pen $10 \mathrm{U}$ ) sulfazotrim (Sut $25 \mu \mathrm{g}$ ), and tetracycline (Tcy $30 \mu \mathrm{g}$ ). For the antibiogram test, bacterial density was previously adjusted to a $10^{8} \mathrm{UFC} \mathrm{mL}^{-1}$ concentration, by bacterial suspension in saline solution with $1 \%$ turbidity equivalent to the McFarland nephelometer scale 0.5 . Suspensions with standard densities were inoculated with "swab" in Petri dishes containing Mueller-Hinton Agar (Difco) medium with $1 \% \mathrm{NaCl}$, and then antibiotic disks (Laborclin) were applied. The plates were incubated at $35^{\circ} \mathrm{C} / 24 \mathrm{~h}$. The inhibition halos were measured $(\mathrm{mm})$ with digital caliper (Digmess) and since there are no breakpoints defined for Vibrio, we use the zone diameter interpretive standards for Enterobacteriaceae cited by CLSI [11].

In order to determine the antibiotic resistance mediation, resistant strains were selected and subjected to plasmid curing by acridine orange (Sigma A-6014) [12]. All resistant strains were grown in Luria Bertani broth, supplemented with $0.100 \mathrm{mg} \mathrm{mL}^{-1}$ of acridine orange, incubated at $35^{\circ} \mathrm{C}$ for $24 \mathrm{~h}$. Subsequently, inocula were removed and pour-plated in TSA containing $1 \% \mathrm{NaCl}$, incubated at $35^{\circ} \mathrm{C}$ for $24 \mathrm{~h}$. From TSA growth, antibiogram was performed as mentioned above. The resistance was considered chromosomal when observed after the curing procedure; otherwise, it was characterized as plasmid.

\section{Results and Discussion}

The strains used in this study were subjected to biochemical identification only. For the genus Vibrio, the phenotypic identification is still considered not enough, since many species can be misidentified. However, the identification of all strains used was validated [9] and previously published [8].

The resistance to at least one antibiotic was observed in 75 strains (Table 1). The only species susceptible to all drugs was $V$. neptunius. In contrast, resistance was verified and confirmed in all V. parahaemolyticus, V. xuii, V. cholerae,
$V$. alginolyticus, $V$. diazotrophicus, and $V$. vulnificus B3 strains. The isolates of $V$. navarrensis, $V$. brasiliensis, and $V$. coralliilyticus showed high resistance of $71.7 \%, 60 \%$, and $60 \%$, respectively.

Table 2 describes data related to nine profiles of 75 resistant vibrios. The most frequent profile was the resistance to penicillin alone $(n=42)$, followed by the cross-resistance to $\beta$-lactams $(n=20)$ and the multidrug resistance $(n=13)$.

Vibrios antibiotic-resistant have been detected in different species of shrimp $[4,6,13-16]$. The expression of this type of resistance is often related to inappropriate use of antibacterial drugs in aquaculture $[17,18]$.

In a research on antimicrobial susceptibility pattern of $V$. parahaemolyticus derived from shrimp, Bhattacharya et al. [3] revealed the occurrence of strains resistant to ampicillin and sensitive to nalidixic acid and nitrofurantoin. These findings may be compared to the ones from this study, since three strains of $V$. parahaemolyticus were resistant to ampicillin, and all were sensitive to the other antibiotics tested (Table 1). Expression of ampicillin [19] and tetracycline [20] resistance by vibrios from shrimp farming regions has been reported.

Recently, Laganà et al. [21] isolated from Italian aquaculture (fish, shellfish, and crustaceans) sites bacteria (Vibrio spp. and Photobacterium damsela spp. piscicida) resistant to $\beta$-lactams (ampicillin, carbenicillin, mezlocillin, piperacillin, cephalothin, cefazolin, cefuroxime, cefoxitin, ceftazidime, and aztreonam), quinolones (cinoxacin, nalidixic acid, oxolinic acid, and pipemidic acid), potentiated sulfonamides (sulfamethoxazole + trimethoprim), polymyxin (colistin sulphate), fosfomycin, tetracycline, and RNA synthesis inhibitors (rifampicin). Our results also showed levels of resistance to beta-lactam antibiotics, including crossresistance $($ Pen + Cpl, Pen + Atm, Pen + Amp, Cro + Atm, and Pen $+\mathrm{Cpl}+\mathrm{Amp})($ Table 2).

In Brazil, Vibrio resistant to antibacterial drugs has been detected in farmed shrimp and cultivation area. Costa et al. [22] detected Vibrio strains resistant to ampicillin, sulfazotrim, and ceftriaxone in samples of Litopenaeus vannamei shrimp and suggested that the penaeid and its culture environment may constitute the main sources of resistant bacteria. In the present study, a strain with cross-resistance to ceftriaxone and aztreonam was verified; however, there was no resistance to sulfazotrim. Melo et al. [23] reported rates of $90 \%$ and $60 \%$ antibiotic resistance to ampicillin and amikacin in $V$. parahaemolyticus strains isolated from pondreared L. vannamei. Helena Rebouças et al. [10] showed a high incidence of resistance to ampicillin (45.2\%) and to the tetracycline class (38.7\%) in vibrios isolated from marine shrimp farming environments.

The high rate $(68 \%)$ of resistance to penicillin G observed in the present study should be emphasized (Tables 1 and 2). The occurrence of penicillin-resistant vibrios has already been reported in different penaeid culture areas and regions $[6,24]$. Srinivasan and Ramasamy [25] detected $100 \%$ resistance to penicillin $\mathrm{G}$ in vibrios species associated with viral diseased shrimp in India and alert to the environmental, economic, and management problems that may result from the emergence of drug resistant microbial diseases in aquaculture. 
TABLE 2: Antimicrobial resistance pattern in vibrios isolated from the hemolymph of Litopenaeus vannamei shrimp.

\begin{tabular}{llcl}
\hline Classification & Profile & $n$ & Species (number of resistant isolates) \\
\hline $\begin{array}{l}\text { Monoresistance } \\
(n=42)\end{array}$ & Pen & 38 & V. navarrensis (28), V. xuii (4), V. coralliilyticus (3), V. brasiliensis (2), and V. alginolyticus (1) \\
& Atm & 4 & V. navarrensis (3) and V. diazotrophicus (1) \\
Cross-resistance to & Pen + Cpl & 9 & V. navarrensis (3), V. brasiliensis (3), V. xuii (2), and V. parahaemolyticus (1) \\
$\beta$-lactam & 5 & V. navarrensis (4) and V. cholerae (1) \\
$(n=20)$ & Pen + Amp & 2 & V. navarrensis (2) \\
& Cro + Atm & 1 & V. navarrensis (1) \\
& Pen + Cpl + Amp & 3 & V.xuii (2) and V. brasiliensis (1) \\
Multiple resistance & Pen + Tcy & 8 & V.parahaemolyticus (6), V. cholerae (1), and V. vulnificus (1) \\
$(n=13)$ & Pen + Tcy + Amp & 5 & V.parahaemolyticus (3) and V. cholerae (2) \\
\hline
\end{tabular}

${ }^{*} n$ : number of resistant isolates; Pen: penicillin G; Tcy: tetracycline; Amp: ampicillin; Cpl: cephalothin; Atm: aztreonam; Cro: ceftriaxone.

TABLE 3: Plasmid mediation of antimicrobial resistance in vibrios isolated from the hemolymph of Litopenaeus vannamei shrimp.

\begin{tabular}{lcccc}
\hline $\begin{array}{l}\text { Strain } \\
\text { code }\end{array}$ & Species & \multirow{2}{*}{ Resistance profile } & \multicolumn{2}{c}{ Posthealing profile } \\
Resistant & Sensitive \\
\hline$\# 1$ & V. coralliilyticus & Pen & - & Pen \\
$\# 2$ & V. navarrensis & Pen & - & Pen \\
$\# 3$ & V. navarrensis & Pen + Amp & - & Pen + Amp \\
$\# 4$ & V. navarrensis & Pen + Amp & Pen & Amp \\
$\# 9$ & V. navarrensis & Pen & - & Pen \\
$\# 10$ & V. navarrensis & Pen & - & Pen \\
$\# 17$ & V. navarrensis & Pen + Atm & - & Pen + Atm \\
$\# 18$ & V. navarrensis & Pen + Atm & Atm & Pen \\
$\# 36$ & V. navarrensis & Pen & - & Pen \\
$\# 56$ & V. navarrensis & Pen & - & Pen \\
$\# 69$ & V. navarrensis & Pen + Atm & Atm & Pen \\
$\# 74$ & V. brasiliensis & Pen & - & Pen \\
$\# 94$ & V. brasiliensis & Pen & - & Pen \\
$\# 98$ & V. brasiliensis & Pen & - & Pen \\
\hline
\end{tabular}

* Pen: penicillin; Amp: ampicillin; Atm: aztreonam.

Plasmid resistance was characterized for Pen $(n=11)$, Pen $+\operatorname{Amp}(n=1)$, Pen $+\operatorname{Atm}(n=1)$, and Amp $(n=$ 1) (Table 3 ). Resistance to antimicrobial drugs by the other strains $(n=86)$ was possibly mediated by chromosomal genes.

In the present study only phenotypic detection of plasmids was performed. The curing by acridines has been used since 1960s and normally involves loss of the whole plasmid [26]. In 1970s, Dastidar et al. [27] demonstrated the efficiency of acridine orange in the elimination of $\mathrm{R}$ plasmids in Vibrio cholerae multidrug-resistant strains. The acridine orange eliminates plasmids from prokaryotic cells [28], and although the conventional methods for curing plasmids by curing agents may induce mutations in the host chromosomal DNA [29], its use in plasmid detection is still being reported in clinical strains [30] and animal/environmental isolates $[11,31,32]$.
In 13 strains, the resistance to penicillin $G$ was characterized as plasmid (Table 3). In bacteria of the genus Vibrio, the existence of penicillin-resistant encoding plasmid was suggested by Reid and Amyes [33], who described plasmid SAR-1 as capable of hydrolyzing the antibiotics carbenicillin and penicillin $\mathrm{G}$. According to the authors, the most common resistance mechanism to $\beta$-lactam antibiotics is the production of $\beta$-lactamase enzymes, which hydrolyze the antibiotic and inactivate it.

We detected two strains with the plasmid resistance to ampicillin (Table 3). Teo et al. [34] associated the ampicillin resistance in vibrios with a possible via of mediation by $\beta$ lactamase blaVHW-1 and blaVHH-1 genes of approximately $60 \mathrm{~kb}$ present in plasmids.

Molina-Aja et al. [12], in a study of plasmid pattern and antibiotic resistance in Vibrio strains isolated from penaeid, detected an incidence of isolates resistant to cephalothin higher than the present study, with $36.1 \%$ of the strains carrying resistance to this $\beta$-lactam. The same authors attributed to a $21,226 \mathrm{pb}$ plasmid the ability to encode the resistance to cephalothin, thus characterizing that resistance as plasmid. This result should not be compared to the ones in the present study, since the resistance to cephalothin observed in 12 strains was, possibly, of chromosome nature.

\section{Conclusions}

The findings of this study support the conclusion that the cultured shrimps can be vehicles of vibrios resistant to $\beta$ lactam and tetracycline. Thus, the emergence of resistant bacteria to antibacterial drugs may be indicative of the indiscriminate use of these drugs in the cultivation of aquatic organisms. Furthermore, the detection of resistance mediated by mobile genetic elements, plasmids, serves as alert to the possibility of horizontal transfer of antibiotic resistance genes among bacteria.

\section{Conflict of Interests}

The authors declare that there is no conflict of interests regarding the publication of this paper. 


\section{Acknowledgments}

The first author received a scholarship from the Coordenação de Aperfeiçoamento de Pessoal de Nível Superior (CAPES). Thanks are due to Jorge Luiz Adeodato Júnior for help with the English translation.

\section{References}

[1] C. N. Johnson, "Fitness factors in vibrios : a mini-review," Microbial Ecology, vol. 65, no. 4, pp. 826-851, 2013.

[2] T. W. Flegel, "Historic emergence, impact and current status of shrimp pathogens in Asia," Journal of Invertebrate Pathology, vol. 110, no. 2, pp. 166-173, 2012.

[3] M. Bhattacharya, P. Choudhury, and R. Kumar, "Antibiotic- and metal-resistant strains of Vibrio parahaemolyticus isolated from shrimps," Microbial Drug Resistance, vol. 6, no. 2, pp. 171-172, 2000.

[4] A. Roque, A. Molina-Aja, C. Boln-Meja, and B. Gomez-Gil, "In vitro susceptibility to 15 antibiotics of vibrios isolated from penaeid shrimps in Northwestern Mexico," International Journal of Antimicrobial Agents, vol. 17, no. 5, pp. 383-387, 2001.

[5] A. B. Thakur, R. B. Vaidya, and S. A. Suryawanshi, "Pathogenicity and antibiotic susceptibility of Vibrio species isolated from moribund shrimps," Indian Journal of Marine Sciences, vol. 32, no. 1, pp. 71-75, 2003.

[6] B. Vaseeharan, P. Ramasamy, T. Murugan, and J. C. Chen, "In vitro susceptibility of antibiotics against Vibrio spp. and Aeromonas spp. isolated from Penaeus monodon hatcheries and ponds," International Journal of Antimicrobial Agents, vol. 26, no. 4, pp. 285-291, 2005.

[7] F. C. Cabello, "Heavy use of prophylactic antibiotics in aquaculture: a growing problem for human and animal health and for the environment," Environmental Microbiology, vol. 8, no. 7, pp. 1137-1144, 2006.

[8] R. Albuquerque-Costa, R. Lima-Araújo, and R. H. Silva dos Fernandes-Vieira, "Phenotyping of vibrios isolated from marine shrimp hemolymph," Ciencias Marinas, vol. 39, no. 3, pp. 317321, 2013.

[9] I. Noguerola and A. R. Blanch, "Identification of Vibrio spp. with a set of dichotomous keys," Journal of Applied Microbiology, vol. 105, no. 1, pp. 175-185, 2008.

[10] R. Helena Rebouças, O. Viana de Sousa, A. Sousa Lima, F. Roger Vasconcelos, P. B. de Carvalho, and R. H. S. dos Fernandes Vieira, "Antimicrobial resistance profile of Vibrio species isolated from marine shrimp farming environments (Litopenaeus vannamei) at Ceará, Brazil," Environmental Research, vol. 111, no. 1, pp. 21-24, 2011.

[11] Clinical and Laboratory Standards Institute, Performance Standards for Antimicrobial Susceptibility Testing: Twentieth Informational Supplement M100-S20, Clinical and Laboratory Standards Institute, Wayne, Pa, USA, 2010.

[12] A. Molina-Aja, A. García-Gasca, A. Abreu-Grobois, C. BolánMejía, A. Roque, and B. Gomez-Gil, "Plasmid profiling and antibiotic resistance of Vibrio strains isolated from cultured penaeid shrimp," FEMS Microbiology Letters, vol. 213, no. 1, pp. 7-12, 2002.

[13] E. Molitoris, S. W. Joseph, M. I. Krichevsky, W. Sindhuhardja, and R. R. Colwell, "Characterization and distribution of Vibrio alginolyticus and Vibrio parahaemolyticus isolated in Indonesia," Applied and Environmental Microbiology, vol. 50, no. 6, pp. 1388-1394, 1985.
[14] T. J. Abraham, R. Manley, R. Palaniappan, and K. Dhevendaran, "Pathogenicity and antibiotic sensitivity of luminous Vibrio harveyi isolated from diseased penaeid shrimp," Journal of Aquaculture in the Tropics, vol. 12, no. 1, pp. 1-8, 1997.

[15] E. A. Tendencia and L. D. de la Pena, "Antibiotic resistance of bacteria from shrimp ponds," Aquaculture, vol. 195, no. 3-4, pp. 193-204, 2001.

[16] M. Uyaguari, P. Key, J. Moore, K. Jackson, and G. Scott, "Acute effects of the antibiotic oxytetracycline on the bacterial community of the grass shrimp, Palaemonetes pugio," Environmental Toxicology and Chemistry, vol. 28, no. 12, pp. 2715-2724, 2009.

[17] J. Li, J. Yie, R. W. T. Foo, J. M. L. Ling, H. Xu, and N. Y. S. Woo, "Antibiotic resistance and plasmid profiles of Vibrio isolates from cultured silver sea bream, Sparus sarba," Marine Pollution Bulletin, vol. 39, pp. 245-249, 1999.

[18] K. Holmström, S. Gräslund, A. Wahlström, S. Poungshompoo, B.-E. Bengtsson, and N. Kautsky, "Antibiotic use in shrimp farming and implications for environmental impacts and human health," International Journal of Food Science and Technology, vol. 38, no. 3, pp. 255-266, 2003.

[19] T. Nakayama, E. Ito, N. Nomura, and M. Matsumura, "Comparison of Vibrio harveyi strains isolated from shrimp farms and from culture collection in terms of toxicity and antibiotic resistance," FEMS Microbiology Letters, vol. 258, no. 2, pp. 194199, 2006.

[20] O. L. Akinbowale, H. Peng, and M. D. Barton, "Diversity of tetracycline resistance genes in bacteria from aquaculture sources in Australia," Journal of Applied Microbiology, vol. 103, no. 5, pp. 2016-2025, 2007.

[21] P. Laganà, G. Caruso, E. Minutoli, R. Zaccone, and S. Delia, "Susceptibility to antibiotics of Vibrio spp. and Photobacterium damsela ssp. piscicida strains isolated from italian aquaculture farms," New Microbiologica, vol. 34, no. 1, pp. 53-63, 2011.

[22] R. A. Costa, G. H. F. Vieira, G. C. Silva et al., "Susceptibilidade "in vitro" a antimicrobianos de estirpes de Vibrio spp. isoladas de camarões (Litopenaeus vannamei) e de água de criação destes animais provenientes de uma fazenda de camarões no Ceará," Brazilian Journal of Veterinary Research and Animal Science, vol. 45, pp. 458-462, 2008.

[23] L. M. R. de Melo, D. Almeida, E. Hofer et al., "Antibiotic resistance of Vibrio parahaemolyticus isolated from pond-reared Litopenaeus vannamei marketed in Natal, Brazil," Brazilian Journal of Microbiology, vol. 42, no. 4, pp. 1463-1469, 2011.

[24] L. Jayasree, P. Janakiram, and R. Madhavi, "Characterization of Vibrio spp. associated with diseased shrimp from culture ponds of Andhra Pradesh (India)," Journal of the World Aquaculture Society, vol. 37, no. 4, pp. 523-532, 2006.

[25] P. Srinivasan and P. Ramasamy, "Occurrence, distribution and antibiotic resistance patterns of Vibrio species associated with viral diseased shrimp of South Indian aquaculture environment," International Journal of Agriculture Sciences, vol. 1, pp. 1-10, 2009.

[26] V. Salisbury, R. W. Hedges, and N. Datta, "Two modes of "curing" transmissible bacterial plasmids," Journal of General Microbiology, vol. 70, no. 3, pp. 443-452, 1972.

[27] S. G. Dastidar, R. Poddar, R. Kumar, and A. N. Chakrabarty, "Incidence and elimination of R plasmids in Vibrio cholerae," Antimicrobial Agents and Chemotherapy, vol. 11, no. 6, pp. 10791080, 1977.

[28] H. D. Kumar and A. K. Tripathi, "Mutagenic and plasmideliminating action of acridine orange in the cyanobacterium Nostoc," Current Science, vol. 57, no. 17, pp. 845-852, 1985. 
[29] X. Liu, D. Wang, H. Wang, E. Feng, and L. Zhu, "Curing of plasmid pXO1 from Bacillus anthracis using plasmid incompatibility," PLoS ONE, vol. 7, no. 1, Article ID e29875, 2012.

[30] S. Barman, S. Chatterjee, G. Chowdhury et al., "Plasmidmediated streptomycin and sulfamethoxazole resistance in Shigella flexneri 3a," International Journal of Antimicrobial Agents, vol. 36, no. 4, pp. 348-351, 2010.

[31] A. S. Kamat and C. K. K. Nair, "Evidence for plasmid-mediated toxin production in Bacillus cereus BIS-59," World Journal of Microbiology \& Biotechnology, vol. 8, no. 2, pp. 210-211, 1992.

[32] F. C. T. Carvalho, O. V. Sousa, E. M. R. Carvalho, E. Hofer, and R. H. S. F. Vieira, "Antibiotic resistance of Salmonella spp. isolated from shrimp farming freshwater environment in Northeast region of Brazil," Journal of Pathogens, vol. 2013, Article ID 685193, 5 pages, 2013.

[33] A. J. Reid and S. G. B. Amyes, "Plasmid penicillin resistance in Vibrio cholerae: identification of new $\beta$-lactamase SAR-1," Antimicrobial Agents and Chemotherapy, vol. 30, no. 2, pp. 245247, 1986.

[34] J. W. P. Teo, A. Suwanto, and C. L. Poh, "Novel $\beta$-lactamase genes from two environmental isolates of Vibrio harveyi," Antimicrobial Agents and Chemotherapy, vol. 44, no. 5, pp. 13091314, 2000. 

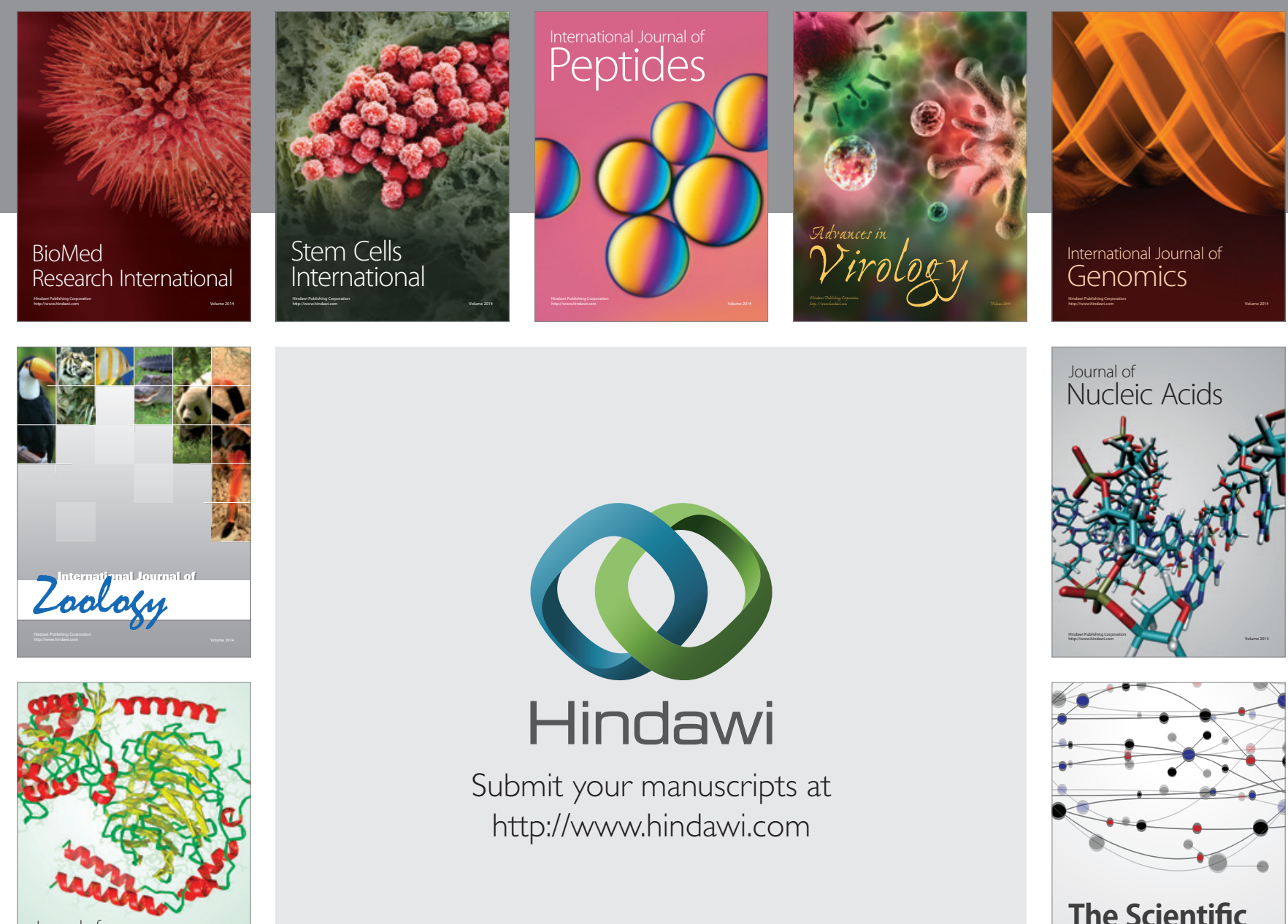

Submit your manuscripts at

http://www.hindawi.com

Journal of
Signal Transduction
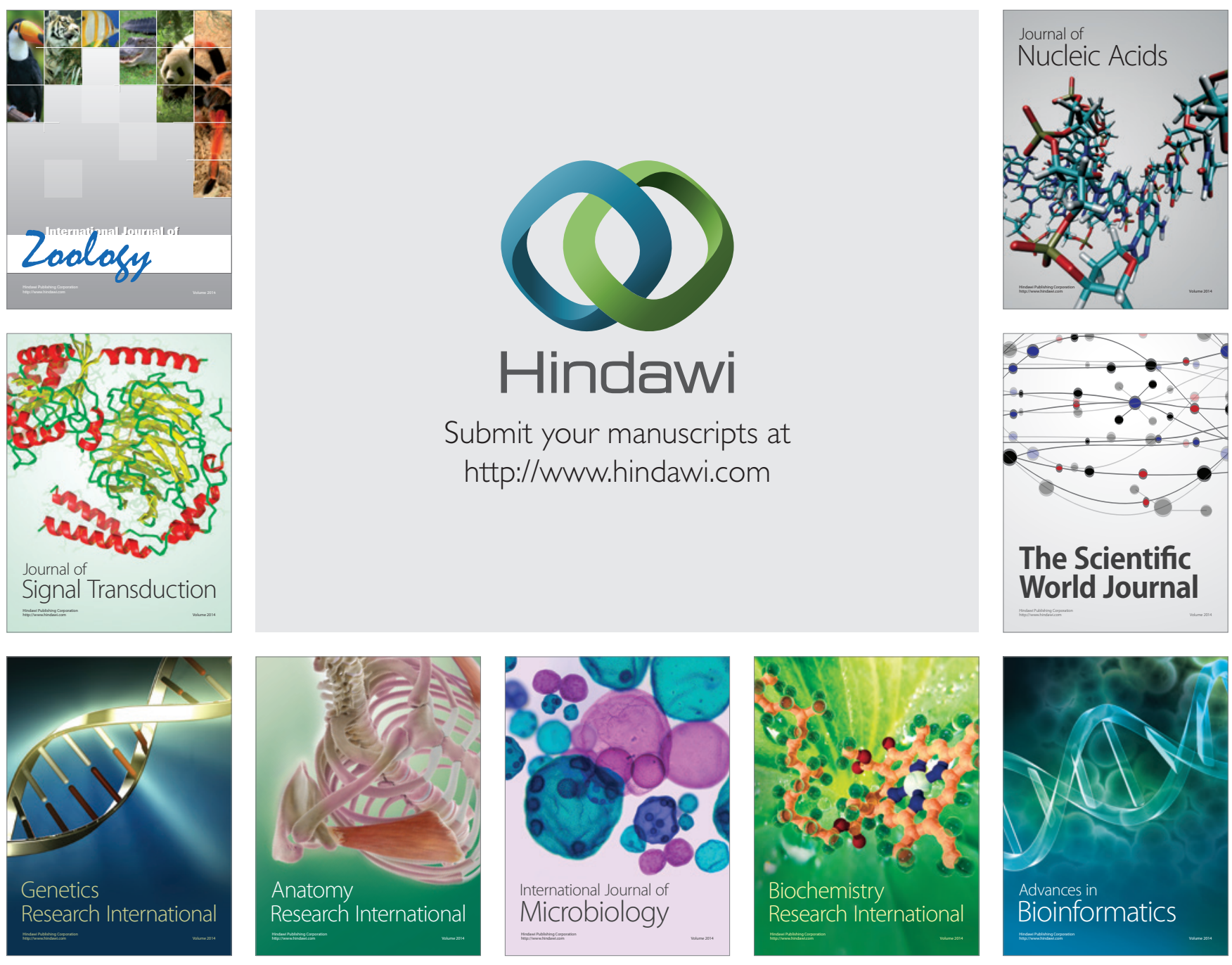

The Scientific World Journal
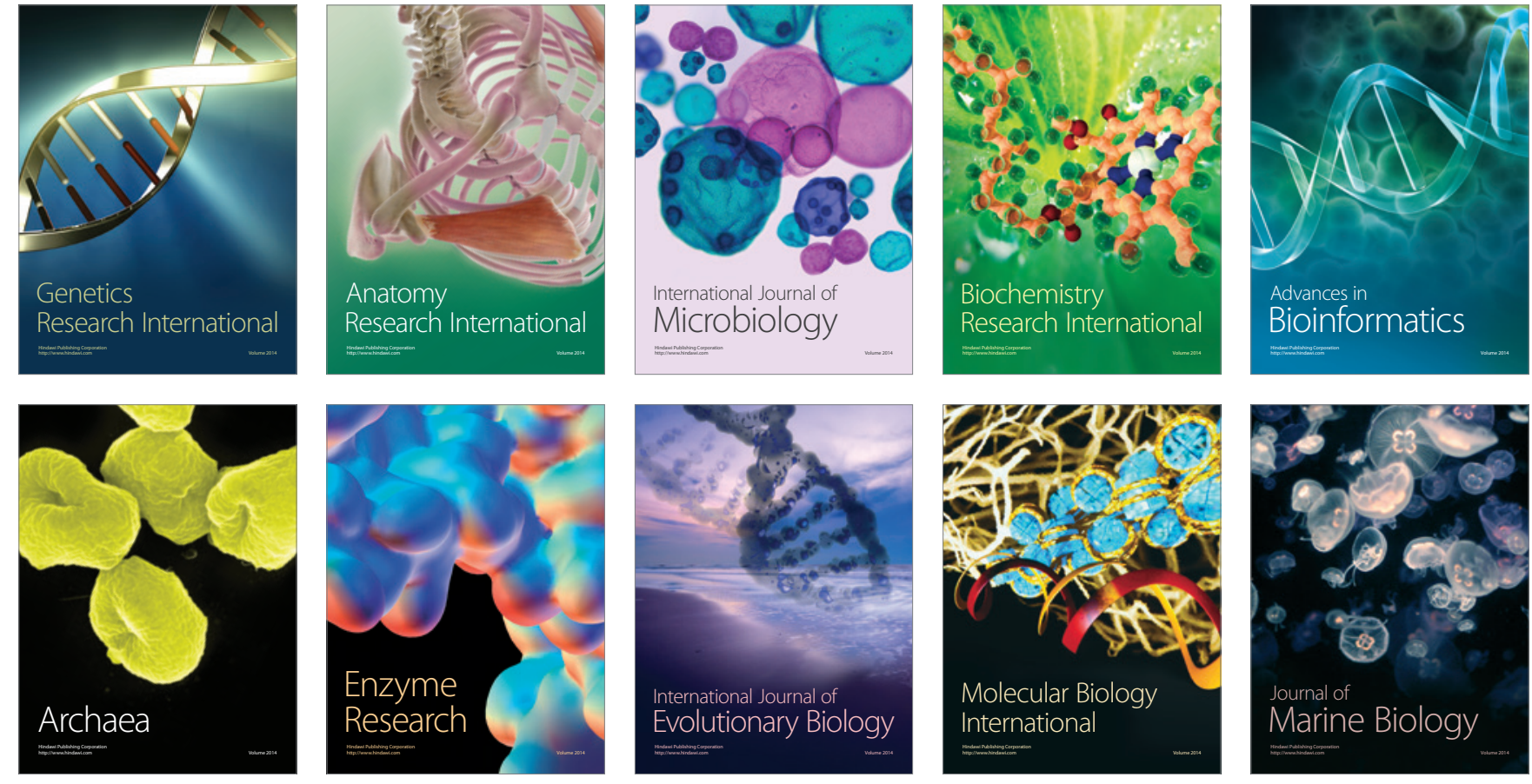